\title{
The first reported aspiration thrombectomy with a guide extension mother-and-child catheter in ST elevation myocardial infarction due to bacterial vegetation coronary artery embolism
}

\author{
Dariusz Ciecwierz ${ }^{1}$, Maksymilian Mielczarek ${ }^{1}$, Milosz Jaguszewski ${ }^{1,2}$, Rafal Peksa ${ }^{3}$, Marcin Gruchala ${ }^{1}$ \\ ${ }^{1}$ First Department of Cardiology, Medical University of Gdansk, Gdansk, Poland \\ 2Department of Cardiology, Campus Benjamin Franklin, Charite Berlin, Berlin, Germany \\ ${ }^{3}$ Department of Pathomorphology, Medical University of Gdansk, Gdansk, Poland
}

Adv Interv Cardiol 2016; 12, 1 (43): 70-72

DOI: $10.5114 /$ pwki.2016.56955

A 74-year-old man presented with ST elevation myocardial infarction (STEMI) on the $15^{\text {th }}$ day of antibiotic therapy due to aortic valve staphylococcal endocarditis. The coronary angiography revealed occlusion of the left anterior descending artery (LAD) (Figure $1 \mathrm{~A}$ ). Initial aspiration thrombectomy (AT) with an Export AP (Medtronic Vascular) catheter reestablished TIMI 3 flow. No trace of ruptured plaque was detected. However, the final contrast injection revealed occlusion of the left circumflex artery (LCX) (Figure $1 \mathrm{~B}$ ), presumably by material translocated during withdrawal of the AT device. Since AT using the Export AP catheter was ineffective in the LCX, a guide extension mother-and-child catheter was applied as an aspiration device [1]. First a $2.0 \times 20$ $\mathrm{mm}$ balloon catheter was inflated beyond the site of the occlusion in order to ensure protection from distal embolism and facilitate the guide extension catheter advancement (Figure $1 \mathrm{C}$ ). Subsequently, the Heartrail II-ST01 $5 \mathrm{Fr}$ (Terumo Medical) catheter was positioned proximal to the site of the occlusion (Figure $1 \mathrm{C}$ ). Aspiration was performed with suction pressure generated by a $20 \mathrm{cc}$ syringe attached to the proximal tip of the guide extension catheter via a y-connector, while the guide wire and balloon catheter remained at their positions. The large body of the embolus was pulled into the syringe (Figure $1 \mathrm{E}$ ), which resulted in TIMI 3 flow restoration (Figure $1 \mathrm{D})$. The patient's further clinical course was uneventful. Histological examination of the aspirated material revealed thrombus with purulent foci, the picture suggestive of bacterial vegetation (Figure $1 \mathrm{~F}$ ).
The greatest shortcoming of the dedicated aspiration catheters is their small inner cross-sectional area (CSA). The suction power is often insufficient to evacuate occlusive material, but intracoronary maneuvers may fragment it; therefore, distal embolization of the infarct related artery is a frequently reported complication [2]. Furthermore, a large thrombus or bacterial vegetation may get stuck at the tip of an aspiration device and be released during its withdrawal, causing embolic stroke or occlusion of another artery.

Frequently, the radial artery may not accommodate guide catheters larger than $6 \mathrm{Fr}$, which precludes the use of larger dedicated AT devices. Previously, in selected cases of STEMI, wherein a large thrombus not amenable to routine AT was identified, aspiration using a deeply advanced guide catheter or a 'Fogarty type' balloon embolectomy has been attempted. These approaches provide the potential for coronary dissections and prolonged ischemic times [3, 4]. Mechanical thrombectomy might also be considered; however, these devices are rarely available "off the shelf". Therefore, AT with guide extension catheters seems the reasonable option. Beside the Heartrail II-STO1 catheter, the GuideLiner (Vascular Solutions) and the Guidezilla (Boston Scientific) catheters may be similarly used for aspiration [5]. The Heartrail II-STO1 catheter is a $120 \mathrm{~cm}$ straight tip $5 \mathrm{Fr}$ catheter that extends throughout the length of the $6 \mathrm{Fr}$ guide catheter, unlike the other two guide extension catheters. Distal protection by balloon occlusion does compromise the inner CSA, possibly limiting the efficacy of AT. An optional approach for distal protection would be a filter wire

\section{Corresponding author:}

Maksymilian Mielczarek MD, First Department of Cardiology, Medical University of Gdansk, 7 Dębinki St, 80-952 Gdansk, Poland, phone: +48 601840 690, fax: +48 5834612 01, e-mail: max.mielczarek@gmail.com

Received: 1.05.2015, accepted: 12.06.2015. 
A

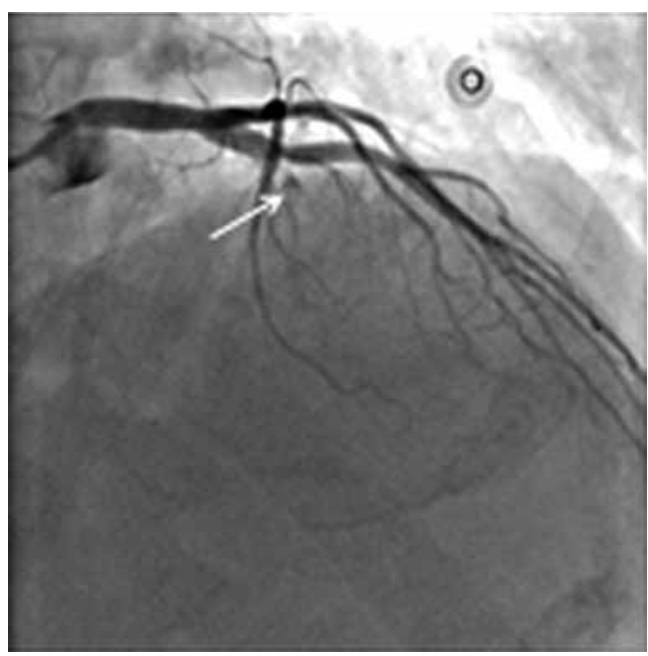

C

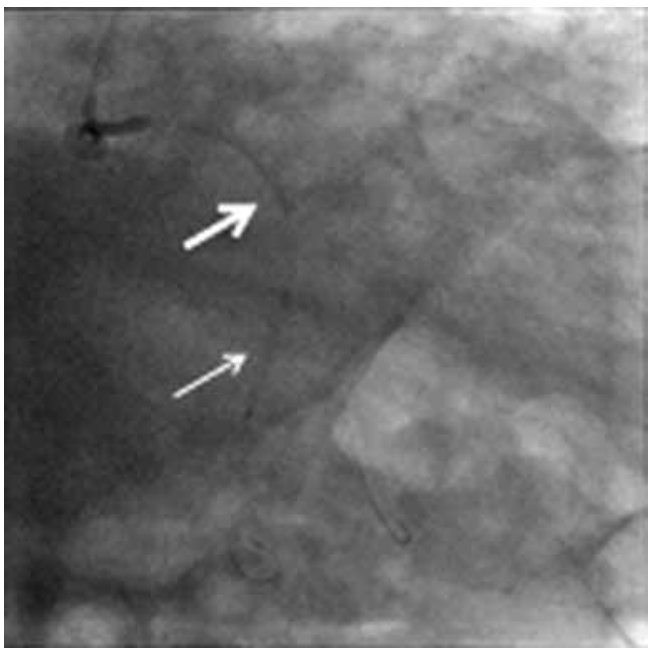

E

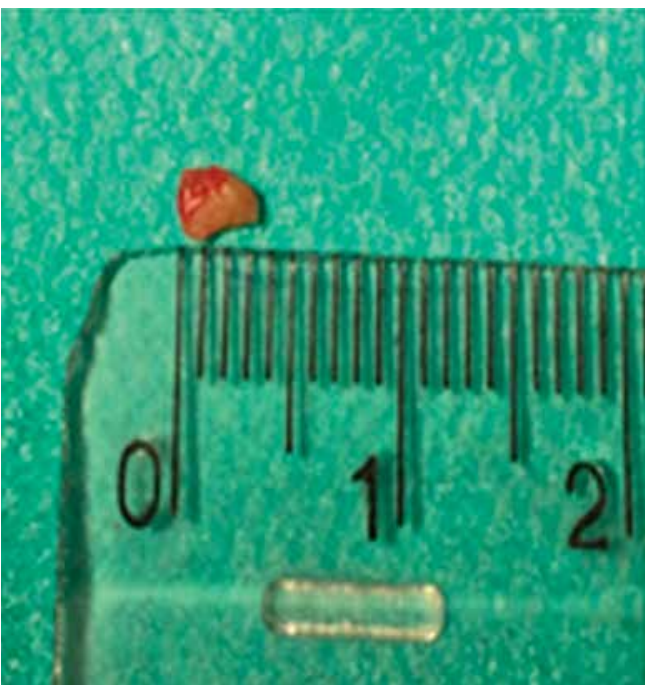

B

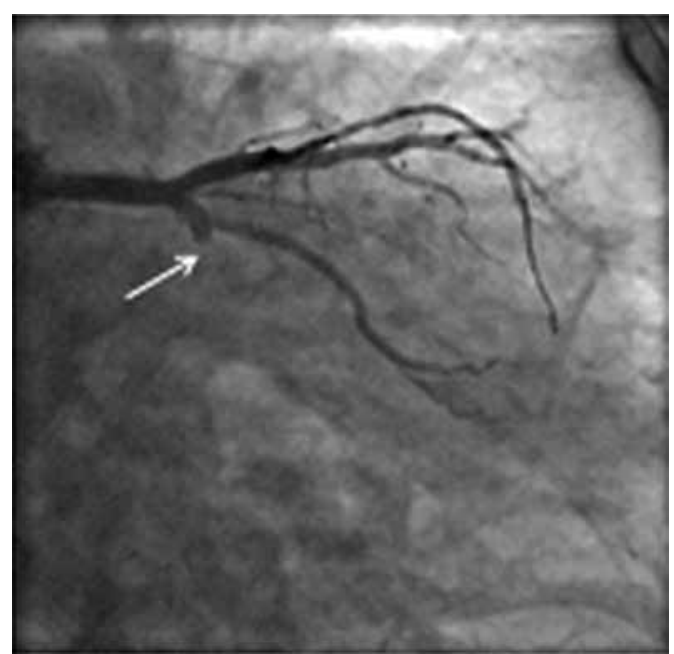

D

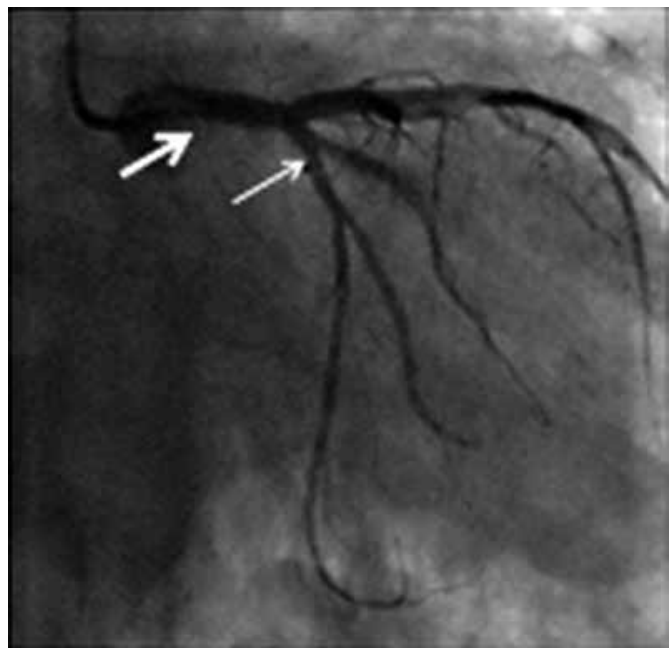

$\mathrm{F}$

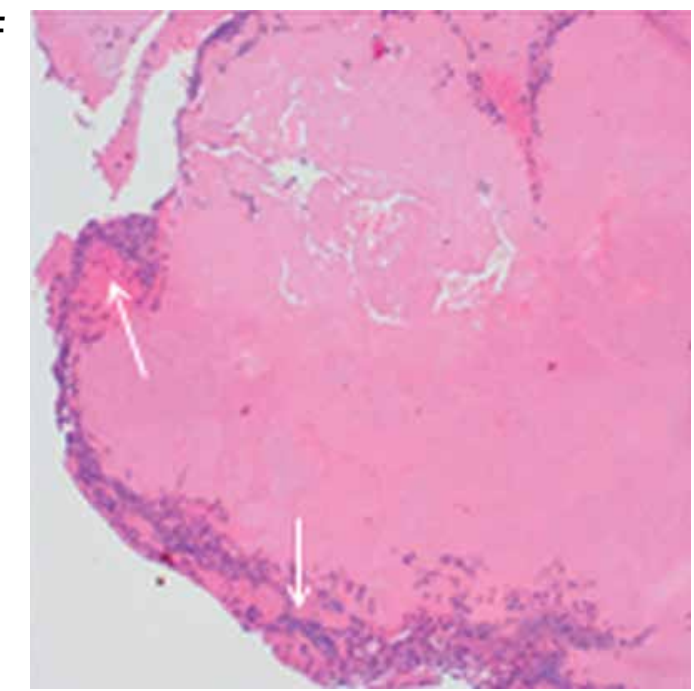

Figure 1. A - Initial angiography, the site of the LAD occlusion (thin arrow) and the patent LCX. B - The site of the LCX occlusion by the material translocated from the LAD during aspiration thrombectomy using the Export AP (thin arrow). C - Manual aspiration thrombectomy with a guide extension mother-and-child catheter (arrow); protection from distal embolism is provided by an inflated balloon catheter (thin arrow). $\mathbf{D}-$ The previous site of the LCX occlusion (thin arrow) after aspiration with a guide extension catheter (arrow) - complete removal of the embolic material. E - Embolic material extracted from the LCX. F - Histopathological specimen of the extracted embolic material, purulent foci within thrombus (thin arrows) 
basket, less likely to compromise the inner CSA of the AT device.

\section{Conflict of interest}

The authors declare no conflict of interest.

\section{References}

1. Mani AJ. Novel use of a guide extension mother-and-child catheter for adjunctive thrombectomy during percutaneous coronary intervention for acute coronary syndromes. J Invasive Cardiol 2014; 26: 249-54.

2. Jolly SS, Cairns JA, Yusuf S, et al.; TOTAL Investigators. Randomized trial of primary $\mathrm{PCI}$ with or without routine manual thrombectomy. N Engl J Med 2015; 372: 1389-98.

3. Pornratanarangsi S, El-Jack SS, Webster MW, et al. Extraction of challenging intracoronary thrombi: multi-device strategies using guide catheters, distal vascular protection devices and aspiration catheters. J Invasive Cardiol 2008; 20: 455-62.

4. Gick M, Jander N, Bestehorn HP, et al. Randomized evaluation of the effects of filter-based distal protection on myocardial perfusion and infarct size after primary percutaneous catheter intervention in myocardial infarction with and without ST-segment elevation. Circulation 2005; 112: 1462-9.

5. Numasawa Y, Motoda H, Yamazaki H, et al. Use of the GuideLiner catheter for aspiration thrombectomy in a patient with ST-elevation myocardial infarction with a large intracoronary thrombus. Cardiovasc Interv Ther 2015 May 7. 